\title{
Atomic Layer Deposition of Ruthenium Thin Films From an Amidinate Precursor
}

\section{Citation}

Wang, Hongtao, Roy G. Gordon, Roger Alvis, and Robert M. Ulfig. Forthcoming. Atomic layer deposition of ruthenium thin films from an amidinate precursor. Chemical Vapor Deposition.

\section{Published Version}

http://www3.interscience.wiley.com/journal/10003226/home

\section{Permanent link}

http://nrs.harvard.edu/urn-3:HUL.InstRepos:3347576

\section{Terms of Use}

This article was downloaded from Harvard University's DASH repository, and is made available under the terms and conditions applicable to Open Access Policy Articles, as set forth at http:// nrs.harvard.edu/urn-3:HUL.InstRepos:dash.current.terms-of-use\#OAP

\section{Share Your Story}

The Harvard community has made this article openly available.

Please share how this access benefits you. Submit a story.

Accessibility 


\section{Atomic Layer Deposition of Ruthenium Thin}

\section{Films from an Amidinate Precursor}

Hongtao Wang

School of Engineering and Applied Science, Harvard University, Cambridge, MA 02138

Roy G. Gordon ${ }^{1}$

Department of Chemistry and Chemical Biology, Harvard University, Cambridge, MA

02138

Roger Alvis

FEI Company, 5350 NE Dawson Creek Drive, Hillsboro, Oregon 97124

Robert M. Ulfig

Imago Scientific Instruments, 5500 Nobel Drive, Madison, WI 53711

Key words: Atomic layer deposition, Ruthenium thin films, $\mathrm{O}_{2}$ exposure

${ }^{1}$ Author to whom correspondence should be addressed; email: gordon@chemistry.harvard.edu 


\begin{abstract}
Ruthenium thin films were deposited by atomic layer deposition from $\operatorname{bis}\left(N, N^{\prime}-\right.$ di-tert-butylacetamidinato)ruthenium(II) dicarbonyl and $\mathrm{O}_{2}$. Highly conductive, dense and pure thin films can be deposited when oxygen exposure $E_{\mathrm{O}}$ approaches a certain threshold $\left(E_{\max }\right)$. When $E_{\mathrm{O}}>E_{\max }$, the film peels off due to the recombinative desorption of $\mathrm{O}_{2}$ at the film/substrate interface. Analysis by an atomic probe microscope shows that the crystallites are nearly free of carbon impurity $(<0.1$ at.\%), while a low level of carbon $(<0.5 \mathrm{at} . \%)$ is segregated near the grain boundaries. The atom probe microscope also shows that a small amount of $\mathrm{O}$ impurity $(0.3$ at.\%) is distributed uniformly between the crystallites and the grain boundaries.
\end{abstract}




\section{Introduction}

Smooth ruthenium thin films with low resistivity and high purity are candidates for various applications in microelectronics such as electrodes for both dynamic random access memories and metal-oxide-semiconductor field effect transistors, ${ }^{[1]}$ and seed layers for copper interconnections. ${ }^{[2]} \mathrm{Ru}$ has a conductive oxide, $\mathrm{RuO}_{2}$, which makes it an ideal substrate for oxide dielectrics deposited with ozone, such as rutile phase $\mathrm{TiO}_{2} \cdot{ }^{[3]} \mathrm{Ru}$ thin films have been deposited by both physical vapor deposition and chemical vapor deposition. However, atomic layer deposition (ALD) is still preferred for conformal deposition for structures with very high aspect ratios.

Several ALD ruthenium precursors have been studied. The cyclopentadienyl $(\mathrm{Cp})$ compounds, such as $\mathrm{RuCp}_{2}$ and $\operatorname{Ru}(\operatorname{EtCp})_{2},{ }^{[2,4,5]}$ and the tris- $\beta$-diketonates (thd) compounds, such as $\mathrm{Ru}(\text { thd })_{3},{ }^{[6]}$ have been studied with $\mathrm{O}_{2}$ as co-reactant. The ruthenium amidinate precursor, bis( $N, N^{\prime}$-di-tert-butylacetamidinato)ruthenium(II) dicarbonyl, has been synthesized in our group and used to deposit ruthenium thin films with or without $\mathrm{NH}_{3}$ as co-reactant. ${ }^{[7,8]}$ Highly pure and conductive films have been conformally deposited in holes with aspect ratio 40:1. ${ }^{[8]}$ In this research, we report an ALD process for ruthenium thin films using this amidinate precursor and $\mathrm{O}_{2}$. We found that the growth mechanism is quite different from the process using $\mathrm{NH}_{3}$ as a co-reactant.

\section{Results and Discussion}

The oxygen exposure has a significant effect on the growth behavior, structure and properties of ALD Ru films. The $\mathrm{O}_{2}$ exposure $\left(E_{\mathrm{O}}\right)$ can be estimated from the number 
of $\mathrm{O}_{2}$ molecules dosed per ALD cycle $\left(n_{\mathrm{O}}\right)$, the pumping speed $(S)$ and the deposition temperature $\left(T_{\mathrm{h}}\right)$ :

$$
E_{\mathrm{O}}=\frac{n_{\mathrm{O}} R T_{\mathrm{h}}}{S}=\frac{P_{\mathrm{O}} V_{\mathrm{O}}}{S} \frac{T_{\mathrm{h}}}{T_{\mathrm{O}}},
$$

where $R$ is the ideal gas constant, $P_{\mathrm{O}}, V_{\mathrm{O}}$ and $T_{\mathrm{O}}$ the pressure, volume $(5 \mathrm{ml})$ and temperature $(413 \mathrm{~K})$ of the $\mathrm{O}_{2}$ trap. The pumping speed $S$ is about $2.71 \cdot \mathrm{s}^{-1}$ for an Edwards vacuum pump RV8 used in this ALD reactor. A first observation is that the growth rate is increased from $\sim 0.3 \AA$ /cycle to $1 \AA$ /cycle after introducing $\mathrm{O}_{2}$ for $\mathrm{Ru}$ films deposited at $325^{\circ} \mathrm{C}$ (figure 1), which may be due to the enhanced surface reactivity of the dissociatively adsorbed oxygen on the surface and the region just below the surface. The growth rate is relatively constant for the $\mathrm{O}_{2}$ exposure from 0.015 Torr's to 0.035 Torr $\cdot \mathrm{s}$. Similar behaviors were also observed in $\operatorname{ALD} \mathrm{Ru}$ film depositions from $\mathrm{Ru}(\text { thd })_{3},{ }^{[6]}$ $\mathrm{RuCp}_{2}{ }^{[4,5]}$ and $\mathrm{Ru}(\mathrm{EtCp})_{2 .}{ }^{[9]}$

Figure 2a shows the electron diffraction (ED) pattern with Si (200) diffraction spots as an internal scale. The calculated lattice spacing and the relative intensity closely match the hexagonal $\mathrm{Ru}$ phase (table 1) from powder X-ray diffraction (XRD) (PCPDF File No. 65-7645). No rings from the $\mathrm{RuO}_{2}$ phase have been observed by ED. Figure $2 \mathrm{~b}$ shows the cross-sectional transmission electrom microscope (TEM) image of a typical Ru film deposited with $\mathrm{O}_{2}$ at $325^{\circ} \mathrm{C}$. The Moiré fringes extend through the thickness indicating that the grain size is comparable to the film thickness. No stacking structure of $\mathrm{RuO}_{2} / \mathrm{Ru}$ was observed. 
X-ray photoelectron spectra (XPS) in figure 3a show that the Ru film has a high oxygen concentration in the topmost layer. After $30 \mathrm{~s} \mathrm{Ar}^{+}(3 \mathrm{keV})$ sputtering cleaning, the oxygen level decreases below the detection limit ( 1\%) of the XPS, which is consistent with the low solubility of oxygen in bulk $\mathrm{Ru}$ and further proves there is no buried $\mathrm{RuO}_{2}$ phase. ${ }^{[10]}$ The XPS spectra did not change after subsequent $\mathrm{Ar}^{+}$sputtering for longer times. The high resolution XPS of O1s (figure 3b) confirms the oxygen peak is comparable to the background noise. No N impurities have been detected. Due to the overlap between $\mathrm{C} 1 \mathrm{~s}$ and $\mathrm{Ru} 3 \mathrm{~d}_{3 / 2}$ peaks, XPS cannot measure the carbon content straightforwardly. However, the low resistivity $(\sim 10 \mu \Omega \cdot \mathrm{cm})$ and high density $(\sim 12.3$ $\mathrm{g} / \mathrm{cm}^{3}$ ) of a $30 \mathrm{~nm}$ ALD Ru film imply that the carbon concentration is also low.

More sensitive detection of impurities was done with atom probe microscopy (APM), which uses the time-of-flight mass spectrometry and the point-projection microscopy to identify where atoms were originally located in the specimen in $3 \mathrm{D} \cdot{ }^{[11,12]}$ A film stack, $\mathrm{Co}_{4} \mathrm{~N}(5 \mathrm{~nm}$, capping layer) / $\mathrm{Ru}(10 \mathrm{~nm}$, region of interest) / WN (3 nm, adhesion layer) (figure 4a), was deposited on a coupon with pre-sharpened Si micro-tips (tip radius $\sim 10 \mathrm{~nm}$, covered with a thin layer of thermal $\mathrm{SiO}_{2}$ ) (figure $4 \mathrm{~b}$ ), which can be directly used as an APM sample without being contaminated by the standard sample preparation. A $10 \mathrm{~nm} \mathrm{Ru}$ film was conformally deposited around the micro-tip, as is shown in the 3D Ru atom mapping (figure 5), in which each dot represents a $\mathrm{Ru}$ atom. Figure 6 shows the elemental depth profiles across the $\mathrm{Co}_{4} \mathrm{~N} / \mathrm{Ru}$ interface. The overlap region of $\mathrm{Co}$ and $\mathrm{Ru}$ is $\sim 1.5 \mathrm{~nm}$, which is same as the surface roughness. $\mathrm{C}$ is concentrated at the interface due to transferring the sample after Ru deposition to another reactor for $\mathrm{Co}_{4} \mathrm{~N}$ capping. The $\mathrm{C}$ tail decreases in the same fashion as $\mathrm{Co}$, which suggests 
that the near-interface impurities come from the surface contamination. The $\mathrm{N}$ profile is $\sim 1 \mathrm{~nm}$ deeper into the $\mathrm{Ru}$ film than $\mathrm{Co}$, which is due to the $\mathrm{N}$ diffusion during $\mathrm{Co}_{4} \mathrm{~N}$ deposition with $\mathrm{NH}_{3}$. A sample without $\mathrm{Co}_{4} \mathrm{~N}$ capping does not show any $\mathrm{N}$ content, which is consistent with XPS observations. The grain structure of the Ru film can be recognized by the greater atomic density in the grain interior comparing to the grain boundary (GB) (figure 7a). The dashed lines in the Ru 2D map indicate the GB locations. Comparing the $2 \mathrm{D}$ map of $\mathrm{C}$ atoms (figure $7 \mathrm{~b}$ ) to the $\mathrm{Ru}$ map shows that the $\mathrm{C}$ atoms mostly segregate along GBs. The local impurity concentration can be calculated by counting the different atom numbers inside a given region. In the GB region (box A), C and $\mathrm{O}$ concentrations are 0.48 at $\%$ and $0.27 \mathrm{at} \%$, while inside the grain (box B), they are 0.08 at $\%$ and 0.27 at $\%$ respectively. The $\mathrm{C}$ concentration decreases by a factor of 6 from the GB to the grain interior, while O concentration remains the same. The line profile across the grain boundary (figure $7 \mathrm{c}$ ) clearly shows that the $\mathrm{C}$ atoms mostly distribute in a $5 \mathrm{~nm}$ wide region near the $\mathrm{GB}$.

$\mathrm{Ru}$ crystals have a hexagonal close packed lattice with $c / a \approx \sqrt{8 / 3}$, which contains interstices of octahedral and tetrahedral types. The octahedral interstice has room for a spherical atom of $0.56 \AA$ radius and the tetrahedral interstice for one of only $0.29 \AA$. The octahedral interstice size is much smaller than the $\mathrm{C}$ atom radius $(0.77 \AA)$, but close to the $\mathrm{O}$ atom radius $(0.60 \AA)$. The atom size determines that $\mathrm{C}$ atoms are most likely to be accommodated in the GB regions, which have more open structure, while $\mathrm{O}$ atoms can distribute inside the crystallites without causing significant distortion of the lattice. Regions with high $\mathrm{C}$ impurity content thus have poor crystallinity and low density as observed along the GBs in our experiments. The average impurity concentration for C 
and $\mathrm{O}$ are $0.30 \pm 0.05$ at. $\%$ and $0.27 \pm 0.03$ at.\% respectively for an interior slab of Ru film not including atoms located in the surface or interface regions. The grains are $\sim 20 \mathrm{~nm}$ in size on the micro-tip and comparable to films deposited on planar substrates (figure 4a).

The $\mathrm{Ru}$ films change abruptly from a specular silver look to a milky look with flakes observable to eye when the $\mathrm{O}_{2}$ exposure is above 0.04 Torr $\cdot \mathrm{s}$ at $325^{\circ} \mathrm{C}$. Scanning electron microscope (SEM) images in figure 8 show that those flakes were not from gas phase reactions but result from the film peeling off the substrate. Since $\mathrm{Ru}$ atoms are mobile under high $\mathrm{O}_{2}$ exposure, the film stress will be reduced at higher $\mathrm{O}_{2}$ exposure. Also the film has a thickness only of $15-30 \mathrm{~nm}$. So the film stress has negligible effect on the film peeling. Therefore, the round bumps indicate that some gas species evolved near the film / substrate interface, causing the film to be detached. This is in contrast to the annealing behavior of $\mathrm{Ru}$ thin films in an $\mathrm{O}_{2}$ gas ambient. No morphology change was observed for Ru films annealed at $325^{\circ} \mathrm{C}$ and 40 torr in $\mathrm{O}_{2}(5 \%)$ and $\mathrm{N}_{2}$ mixture for 30 min (SEM images not shown). For annealing in $\mathrm{O}_{2}$ at more elevated temperatures, the Ru film was seriously roughened by oxidation, instead of peeling. ${ }^{[9]}$

The film peeling during deposition presents a paradox: large amounts of oxygen can be accommodated in $\mathrm{Ru}$ surface or subsurface region (e.g. equivalent to 20 to 30 monolayers for $\mathrm{Ru}(0001))^{[13]}$ while the solubility of oxygen in bulk Ru is exceedingly low. ${ }^{[10]}$ Denoting $C_{\mathrm{O}}, C_{\mathrm{R}}$ and $C_{\mathrm{B}}$ as the concentrations of oxygen in subsurface layer after $\mathrm{O}_{2}$ pulse and after Ru precursor vapor pulse, and the bulk solubility respectively, we expect $C_{\mathrm{O}} \gg C_{\mathrm{R}} \sim C_{\mathrm{B}}$ for a good deposition. Incomplete consumption of subsurface oxygen will lead to $C_{\mathrm{O}}>C_{\mathrm{R}}>C_{\mathrm{B}}$ and formation of a super-saturated layer after many 
ALD cycles. The interstitial oxygen atom has a radius somewhat larger than the octahedral interstice and needs to deform the close-packed Ru atoms for accommodation. As the film grows thicker, the percent of the GB atoms is reduced and the chemical potential for interstitials is increased. The energy can be decreased by lowering the oxygen concentration in three possible ways: (1) diffusion of oxygen to the subsurface layer; (2) recombinative desorption of oxygen after diffusion to the film / substrate interface, ${ }^{[14]}$ and (3) formation of buried $\mathrm{RuO}_{2}$ and escape by further oxidizing some of $\mathrm{RuO}_{2}$ to $\mathrm{RuO}_{x}(x=3$ or 4$){ }^{[15,16]}$ The round bumps imply that the desorption of $\mathrm{O}_{2}$ or $\mathrm{RuO}_{x}$ are most likely the mechanisms.

To distinguish the mechanism (2) from (3), it is critical to see whether the fractured $\mathrm{Ru}$ film is strongly oxidized. The formation of crystalline $\mathrm{RuO}_{2}$ was not observed for films deposited at various temperatures and oxygen exposures by X-ray and electron diffractions. The reason may be that the lattice structures are quite different between $\mathrm{RuO}_{2}$ (tetragonal) and $\mathrm{Ru}$ (hexagonal). Energy is needed to form GBs between two phases, which increases the activation energy barrier for $\mathrm{RuO}_{2}$ nucleation. The amorphous phase of $\mathrm{RuO}_{2}$ can also be excluded because of the good crystallinity ( $30-50$ $\mathrm{nm}$ grain size in figure 8b). ${ }^{[17]}$ Grazing angle XRD (figure $8 \mathrm{c}$ ) shows that all the three main peaks come from the hexagonal $\mathrm{Ru}$ phase and only a very weak peak can possibly be assigned to rutile $\mathrm{RuO}_{2}$ (200), which may be due to post-deposition oxidation of the surface by air exposure. The grain size $(L)$ can also be estimated from the Stokes and Wilson method: ${ }^{[18]}$

$$
L=\frac{\lambda}{\beta \cos \theta},
$$


where $\lambda=1.54 \AA$ is the wavelength of the $\mathrm{Cu} K \alpha$ source, $\beta$ the width of the peak at half maximum, and $\theta$ the peak position. Gaussian fitting of the $\mathrm{Ru}$ (002) peak gave $\beta=0.047^{\circ}$ and the grain size was calculated to be $25 \mathrm{~nm}$ after correcting for the $\mathrm{X}$ ray instrument broadening. These diffraction studies show the film is not strongly oxidized during deposition, which excludes mechanism (3) and suggests that the recombinative desorption of oxygen is the dominant mechanism.

Atomic force microscope (AFM) images (figure 9a-c) of Ru films ( 30nm) deposited at $325^{\circ} \mathrm{C}$ show the grain size increases with $\mathrm{O}_{2}$ exposure. Without $\mathrm{O}_{2}$ as coreactant, the grains are uniformly small, which produces relatively smooth films with root mean square (RMS) roughness $\sim 1.5 \mathrm{~nm}$ for a $\sim 30 \mathrm{~nm}$ film. After introducing $\mathrm{O}_{2}$, some grains grow bigger and the size distribution becomes non-uniform. When $E_{\mathrm{O}}$ is approaching $E_{\max }$, the grain size has a narrower distribution and the crystallinity is improved. The RMS value versus $E_{O}$ is summarized in figure $9 \mathrm{~d}$. The roughness increases from $1.5-1.8 \mathrm{~nm}$ to $2.0-2.5 \mathrm{~nm}$ due to the improved crystallinity achieved under higher $\mathrm{O}_{2}$ exposure.

Figure 10a shows that both the resistivity and density of $\sim 30 \mathrm{~nm}$ Ru films depend on the $\mathrm{O}_{2}$ exposure. At low exposure (e.g. $E_{\mathrm{O}}<0.02 \mathrm{Torr} \cdot \mathrm{s}$ at $\left.325^{\circ} \mathrm{C}\right)$, the film density is around $7-8 \mathrm{~g} / \mathrm{cm}^{3}$. The density quickly increases with $E_{\mathrm{O}}$ and reaches a plateau around the bulk density $\left(12.3 \mathrm{~g} / \mathrm{cm}^{3}\right)$ at $E_{\mathrm{O}} \sim 0.33 \mathrm{Torr} \cdot \mathrm{s}$. The film resistivity is more sensitive to $\mathrm{O}_{2}$ exposure and sharply decreases from $320 \mu \Omega \cdot \mathrm{cm}$ to $14 \mu \Omega \cdot \mathrm{cm}$ with $E_{\mathrm{O}}$ from zero to 0.022 Torr-s. Further increasing $E_{\mathrm{O}}$ to 0.033 Torr-s decreases the resistivity to 9.4 
$\mu \Omega \cdot \mathrm{cm}$, which is $32 \%$ higher than the bulk resistivity $(7.1 \mu \Omega \cdot \mathrm{cm})$. The thin film resistivity is affected by scattering from GBs, impurities, interfaces and surfaces. ${ }^{[19]}$ Because the grain size is approximately equal to the film thickness, the scatteringinduced-resistivity model can be simplified as: ${ }^{[19]}$

$$
\rho=\rho_{0}^{\prime}\left(1+\frac{t_{0}}{t}\right)
$$

where $\rho$ is the thin film resistivity, $\rho_{0}^{\prime}$ the bulk resistivity including the effect of impurity scattering, $t_{0}$ the characteristic length related to the electron mean free path and scattering effects of GBs, interfaces and surfaces, and $t$ the film thickness. By linear fitting $\rho$ to $1 / t$ (figure 10b), we got $\rho_{0}^{\prime}=8.6 \mu \Omega \cdot \mathrm{cm}$ and $t_{0}=6 \mathrm{~nm}$. Thus the resistivity for thick films is extrapolated to be $8.6 \mu \Omega \cdot \mathrm{cm}$, which is $21 \%$ higher than the bulk value. Assuming that both $\mathrm{C}$ and $\mathrm{O}$ have same scattering effect, the rate of the resistivity increase for these impurities can be estimated to be $\sim 2 \mu \Omega \cdot \mathrm{cm} / \mathrm{at} . \%$, which is close to the value for bulk $\mathrm{Cu}$ $\left(1 \mu \Omega \cdot \mathrm{cm} /\right.$ at.\%). ${ }^{[19,20]}$

The deposition temperature has a less pronounced effect than $\mathrm{O}_{2}$ exposure. The maximum $\mathrm{O}_{2}$ exposure for adherent films $\left(E_{\max }\right)$ increases with the deposition temperature, shown in figure $11 \mathrm{a}$. The growth rate increases from $0.5 \AA /$ cycle at $300^{\circ} \mathrm{C}$ to $1.7 \AA /$ cycle at $400^{\circ} \mathrm{C}$ (figure $11 \mathrm{~b}$ ). The increase of $E_{\max }$ with temperature is clearly related to the high growth rate at high temperature, i.e. more Ru precursor molecules can consume more adsorbed oxygen and lower the oxygen concentration in $\mathrm{Ru}$ films. Saturation of the growth rate with increasing temperature was also observed for the 
$\mathrm{Ru}(\text { thd })_{3}$ and $\mathrm{RuCp} \mathrm{p}_{2}$ systems, which suggests these ALD processes follow a reaction mechanism similar to the one discussed by T. Aaltonen et al.: Ru films are deposited by oxidizing the precursor ligands with dissociatively adsorbed oxygen from the subsurface region. ${ }^{[4,6]}$ The resistivity is near $10 \mu \Omega \cdot \mathrm{cm}$ for deposition temperatures from $320^{\circ} \mathrm{C}$ to $400^{\circ} \mathrm{C}$ (figure 11b). Figure 12 shows the AFM image of a $35 \mathrm{~nm}$ Ru film deposited at $400^{\circ} \mathrm{C}$. Both the roughness $(1.9 \mathrm{~nm})$ and crystallinity are similar to the film deposited at $325^{\circ} \mathrm{C}$ (figure $8 \mathrm{c}$ ).

\section{Conclusions}

High quality ruthenium thin films were deposited by ALD with bis $\left(N, N^{\prime}\right.$-di-tertbutylacetamidinato)ruthenium(II) dicarbonyl and $\mathrm{O}_{2}$. The film crystallinity, density, and resistivity strongly depend on the $\mathrm{O}_{2}$ exposure, while the roughness is relatively insensitive to $E_{\mathrm{O}}$. As $E_{\mathrm{O}} \approx E_{\max }$, the films have the lowest resistivity, highest density and best crystallinity ( $\sim 10 \mu \Omega \cdot \mathrm{cm}, \sim 12.3 \mathrm{~g} / \mathrm{cm}^{3}$ and grain size comparable to film thickness). High deposition temperature leads to higher growth rate, but has less effect on the film structures and properties. For deposition temperature range of $320^{\circ} \mathrm{C}-400^{\circ} \mathrm{C}$, the resistivity is $\sim 10 \mu \Omega \cdot \mathrm{cm}$ and roughness is $\sim 2 \mathrm{~nm}$ for $30 \mathrm{~nm}$ films. When $E_{\mathrm{O}}>E_{\max }$, films peel off from the substrate due to the recombinative desorption of $\mathrm{O}_{2}$. The impurities are mainly $\mathrm{O}(0.27 \pm 0.03$ at.\%) and $\mathrm{C}(0.30 \pm 0.05$ at.\%). The $\mathrm{C}$ is mostly segregated along grain boundaries, which are less dense than the grain interiors. The $\mathrm{O}$ is more uniformly dissolved in the $\mathrm{Ru}$ film. The rate of resistivity increase with impurities is estimated to be $\sim 2 \mu \Omega \cdot \mathrm{cm} / \mathrm{at} . \%$, which is comparable to the value of copper $(1 \mu \Omega \cdot \mathrm{cm} / \mathrm{at} . \%)$.

\section{Experimental}


$\mathrm{Ru}$ thin films were deposited in a home-built flow-type tube reactor operated at the base pressure 300 mTorr with bis( $N, N^{\prime}$-di-tert-butylacetamidinato)ruthenium(II) dicarbonyl and $\mathrm{O}_{2}$. The substrate temperature was measured by a thermal couple inside the sample holder. The Ru precursor was kept in a glass bubbler at $140^{\circ} \mathrm{C}$ and delivered to the reactor by $\mathrm{N}_{2}$ carrier gas added to the head space of the bubbler to a pressure of about 10 Torr. This added N2 carrier gas, along with the entrained Ru precursor vapor, was released to the reactor in each ALD cycle. High purity $\mathrm{O}_{2}(99.99 \%)$ was used as coreactant and delivered from a $5 \mathrm{ml}$ trap volume with its pressure controlled by an inline regulator. One ALD cycle consisted of one Ru precursor dose and one $\mathrm{O}_{2}$ dose with $10 \mathrm{~s}$ purging in between. The deposition temperatures varied from $300{ }^{\circ} \mathrm{C}$ to $400{ }^{\circ} \mathrm{C}$. All films were deposited on thermal $\mathrm{SiO}_{2}(300 \mathrm{~nm}) / \mathrm{Si}$ wafers $(1 \mathrm{inch}$ by $1.5 \mathrm{inch})$ with $5 \mathrm{~min}$ UV/Ozone pre-treatment to remove surface organic contamination.

The film resistivity was calculated from the thickness measured by X-ray reflectivity (XRR) (Scintag XDS2000) multiplying the sheet resistance measured by a four-point probe. The morphology was studied by scanning electron microscope (Zeiss FESEM Ultra55) and atomic force microscopy (Asylum MFP-3D). The crystal structure and phase were determined by X-ray diffraction (Scintag XDS2000) and electron diffraction (JEOL 2100). The roughness and crystallinity were characterized using AFM and transmission electron microscopy (JEOL 2100). The impurity concentrations and their distribution in the crystallites were measured by an atomic probe microscope (LEAP 3000X HR). Impurity analysis was also attempted by X-ray photoelectron spectroscopy (XPS ESCA SSX-100). The ALD Ru film density was obtained from the area density by Rutherford back scattering divided by the film thickness from XRR. 


\section{Figure Captions}

Figure 1. The dependence of $\mathrm{Ru}$ thin film growth rate on the $\mathrm{O}_{2}$ exposure at the deposition temperature of $325^{\circ} \mathrm{C}$.

Figure 2. (a) ED and (b) Cross-sectional TEM image of Ru film / Si deposited at $325^{\circ} \mathrm{C}$ with $\mathrm{O}_{2}$ as co-reactant.

Figure 3. (a) XPS spectra ( $\mathrm{Al} K \alpha$ radiation, $h v=1486.6 \mathrm{eV}$ ) of a $30 \mathrm{~nm} \mathrm{Ru}$ thin film with low energy $(3 \mathrm{keV}) \mathrm{Ar}^{+}$sputtering for $0 \mathrm{~s}, 30 \mathrm{~s}$ and $100 \mathrm{~s}$. (b) High resolution XPS spectrum of O1s after $30 \mathrm{~s} \mathrm{Ar}^{+}$sputtering.

Figure 4. (a) Cross-sectional TEM image of the film stack on a planar $\mathrm{SiO}_{2} / \mathrm{Si}$ substrate; (b) SEM image of the pre-sharpened micro-tip.

Figure 5. The 3D mapping of $\mathrm{Ru}$ atoms.

Figure 6. (a) The elemental depth profiles across the Co4N / Ru interface. (b) the details of impurity distribution across the interface.

Figure 7. The 2D atom mappings of (a) Ru and (b) C. In (b), box A and B indicate the area for local impurity concentration calculation. The line in (b) indicates the profiling location. (c) The $\mathrm{C}$ and $\mathrm{O}$ line profile across the GB.

Figure 8. (a) low and (b) high magnification SEM images and (c) grazing angle XRD spectrum of Ru thin film deposited at $325^{\circ} \mathrm{C}$ and $E_{\mathrm{O}}=0.04 \mathrm{Torr} \cdot \mathrm{s}$. 
Figure 9. AFM images of $\sim 30 \mathrm{~nm}$ Ru thin films deposited at $325^{\circ} \mathrm{C}$ with different $\mathrm{O}_{2}$ exposures: (a) 0 Torr $\cdot$; (b) 0.022 Torr $\cdot s$; and (c) 0.034 Torr $\cdot s$. (d) Summary of the RMS roughness versus $\mathrm{O}_{2}$ exposure.

Figure 10. (a) Resistivity and density variation with $\mathrm{O}_{2}$ exposure for ALD films deposited at $325{ }^{\circ} \mathrm{C}$; (b) the thickness dependence of resistivity.

Figure 11. (a) The maximum $\mathrm{O}_{2}$ exposure at different deposition temperatures; (b) the growth rate and resistivity of $\sim 30 \mathrm{~nm}$ Ru films deposited at $E_{\max }$ and different deposition temperatures.

Figure 12. AFM image of a $35 \mathrm{~nm}$ Ru thin film deposited at $400^{\circ} \mathrm{C}$ and $E_{\max }$. The RMS roughness is $1.9 \mathrm{~nm}$.

\section{Table}

Table 1. Comparison of the lattice spacings of rutile $\mathrm{RuO}_{2}$ (PCPDF File No. 88-0322), hexagonal Ru (PCPDF File No. 65-7645) and measurements from ED.

\begin{tabular}{c|c|c|c|c}
\hline \hline \multicolumn{2}{|c|}{ Rutile $\mathrm{RuO}_{2}$} & \multicolumn{2}{|c}{ Hexagonal Ru } & ED \\
\hline plane & $d$-spacing $(\AA)$ & plane & $d$-spacing $(\AA)$ & $d$-spacing $(\AA)$ \\
\hline$(110)$ & 3.177 & $(100)$ & 2.338 & 2.333 \\
\hline$(101)$ & 2.555 & $(002)$ & 2.137 & 2.146 \\
\hline$(200)$ & 2.247 & $(101)$ & 2.051 & 2.052 \\
\hline$(111)$ & 2.221 & $(102)$ & 1.577 & 1.566 \\
\hline$(210)$ & 2.009 & $(110)$ & 1.350 & 1.345 \\
\hline$(211)$ & 1.687 & $(103)$ & 1.216 & 1.219 \\
\hline \hline
\end{tabular}




\section{References}

[1] V. Misra, G. Lucovsky and G. Parsons, MRS Bull. 2002, 27, 212.

[2] O. K. Kwon, J. H. Kim, H. S. Park and S. W. Kang, J. Electrochem. Soc. 2004, 151, G109.

[3] S. K. Kim, G. J. Choi, S. Y. Lee, M. Seo, S. W. Lee, J. H. Han, H. S. Ahn, S. Han and C. S. Hwang, Adv. Mater. 2008, 20, 1429.

[4] T. Aaltonen, A. Rahtu, M. Ritala and M. Leskela, Electrochem. Solid State Lett. 2003, 6, C130.

[5] T. Aaltonen, P. Alen, M. Ritala and M. Leskela, Chem. Vapor Depos. 2003, 9, 45.

[6] T. Aaltonen, M. Ritala, K. Arstila, J. Keinonen and M. Leskela, Chem. Vapor Depos. 2004, 10, 215.

[7] H. Z. Li, T. Aaltonen, Z. W. Li, B. S. Lim and R. G. Gordon, The Open Inorganic Chemistry Journal 2008, 2, 11.

[8] H. Li, D. B. Farmer, R. G. Gordon, Y. Lin and J. Vlassak, J. Electrochem. Soc. 2007, 154, D642.

[9] S. H. Kwon, O. K. Kwon, J. H. Kim, S. J. Jeong, S. W. Kim and S. W. Kang, J. Electrochem. Soc. 2007, 154, H773.

[10] H. Over and A. P. Seitsonen, Science 2002, 297, 2003. 
[11] B. Gault, F. de Geuser, L. T. Stephenson, M. P. Moody, B. C. Muddle and S. P. Ringer, Microsc. Microanal. 2008, 14, 296.

[12] D. N. Seidman, Ann. Rev. Mater. Res. 2007, 37, 127.

[13] Y. D. Kim, H. Over, G. Krabbes and G. Ertl, Top. Catal. 2001, 14, 95.

[14] A. Bottcher and H. Niehus, J. Chem. Phys. 1999, 110, 3186.

[15] R. Blume, H. Niehus, H. Conrad, A. Bottcher, L. Aballe, L. Gregoratti, A. Barinov and M. Kiskinova, J. Phys. Chem. B 2005, 109, 14052.

[16] A. Bottcher, H. Conrad and H. Niehus, J. Chem. Phys. 2000, 112, 4779.

[17] S. J. Park, W. H. Kim, W. J. Maeng, Y. S. Yang, C. G. Park, H. Kim, K. N. Lee, S. W. Jung and W. K. Seong, Thin Solid Films 2008, 516, 7345.

[18] B. E. Warren, X-Ray Diffraction, Dover Publications, INC., New York 1990.

[19] S. M. Rossnagel and T. S. Kuan, J. Vac. Sci. Technol. B 2004, 22, 240.

[20] J. M. E. Harper, E. G. Colgan, C. K. Hu, J. P. Hummel, L. P. Buchwalter and C. E. Uzoh, MRS Bull. 1994, 19, 23. 


\section{Figures}

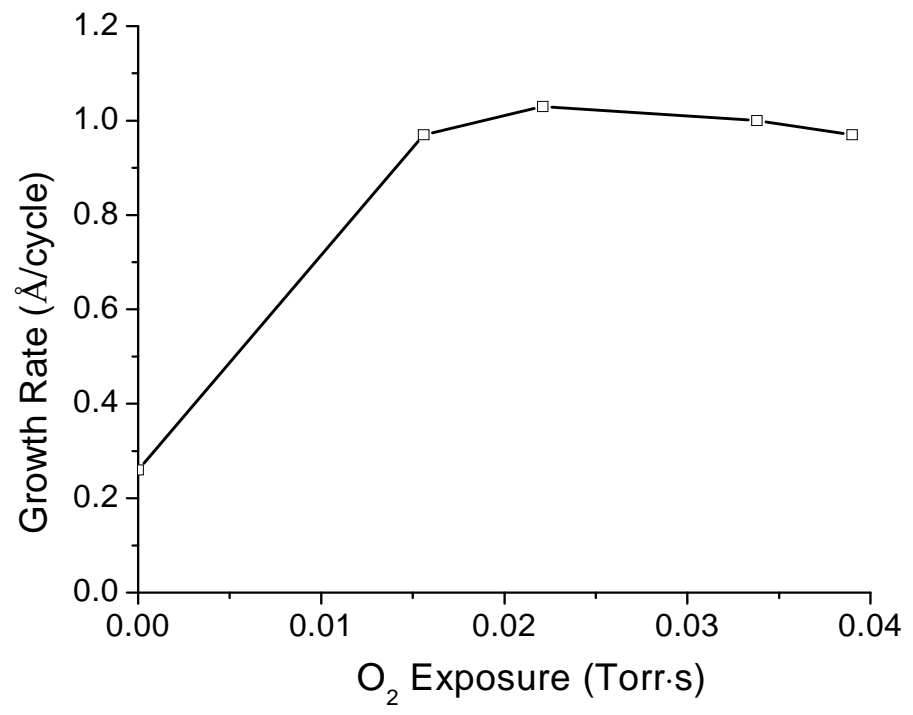

Figure 1. The dependence of $\mathrm{Ru}$ thin film growth rate on the $\mathrm{O}_{2}$ exposure at the deposition temperature of $325^{\circ} \mathrm{C}$. 


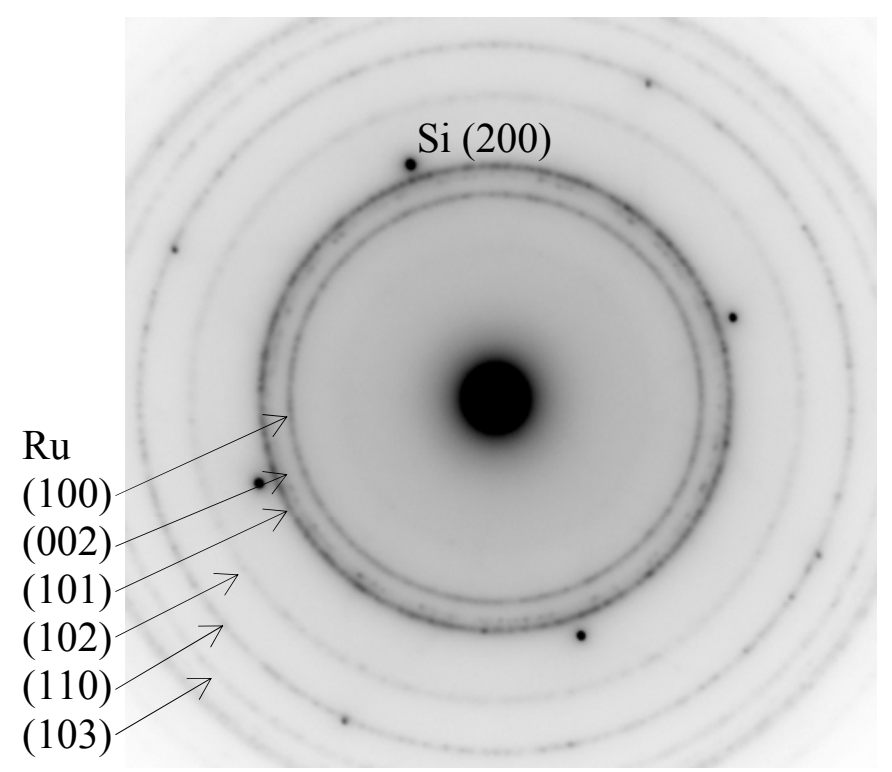

(a)

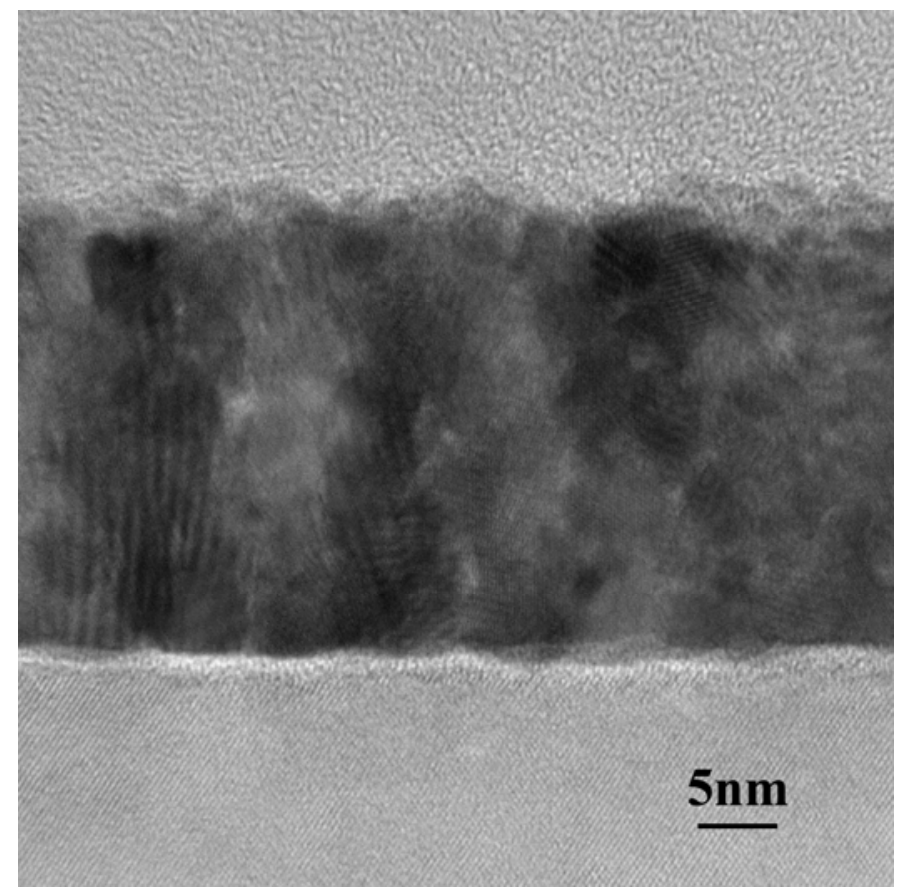

(b)

Figure 2. (a) ED and (b) Cross-sectional TEM image of Ru film / Si deposited at $325{ }^{\circ} \mathrm{C}$ with $\mathrm{O}_{2}$ as co-reactant. 


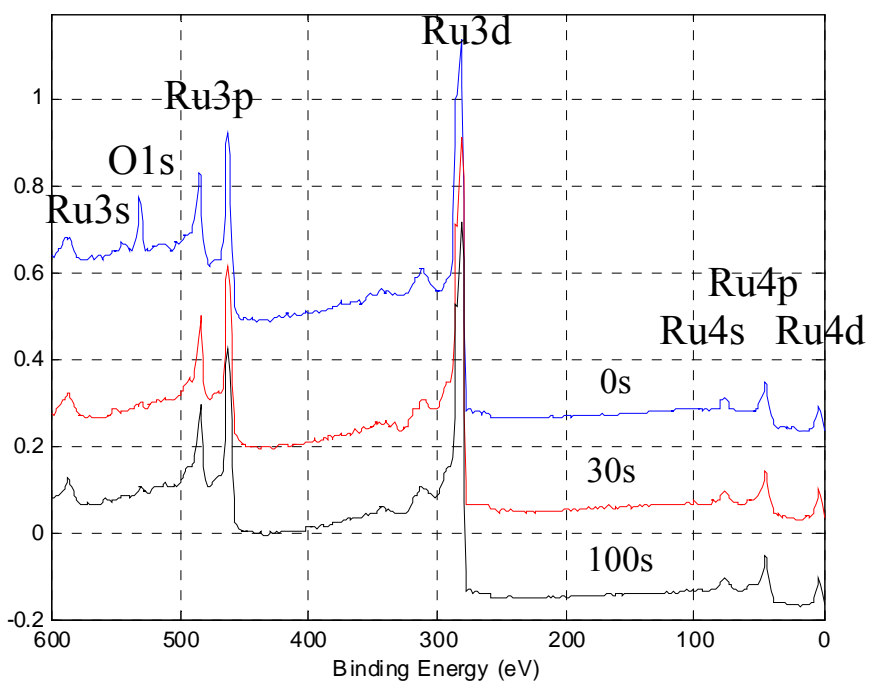

(a)

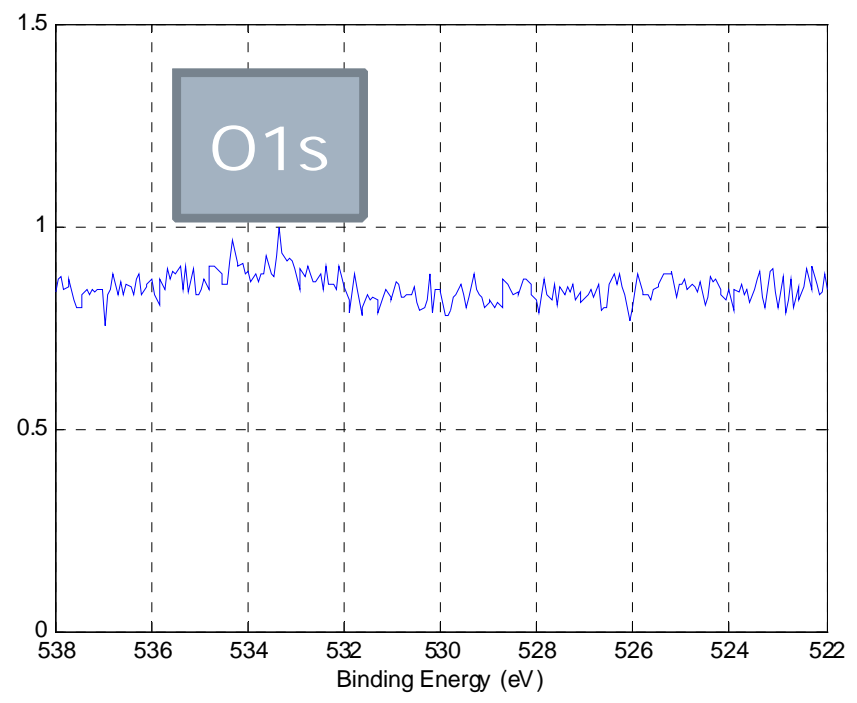

(b)

Figure 3. (a) XPS spectra (Al $K \alpha$ radiation, $h v=1486.6 \mathrm{eV}$ ) of a $30 \mathrm{~nm} \mathrm{Ru}$ thin film with low energy ( $3 \mathrm{keV}$ ) $\mathrm{Ar}^{+}$sputtering for $0 \mathrm{~s}, 30 \mathrm{~s}$ and $100 \mathrm{~s}$. (b) High resolution XPS spectrum of $\mathrm{O} 1 \mathrm{~s}$ after $30 \mathrm{~s} \mathrm{Ar}^{+}$sputtering. 


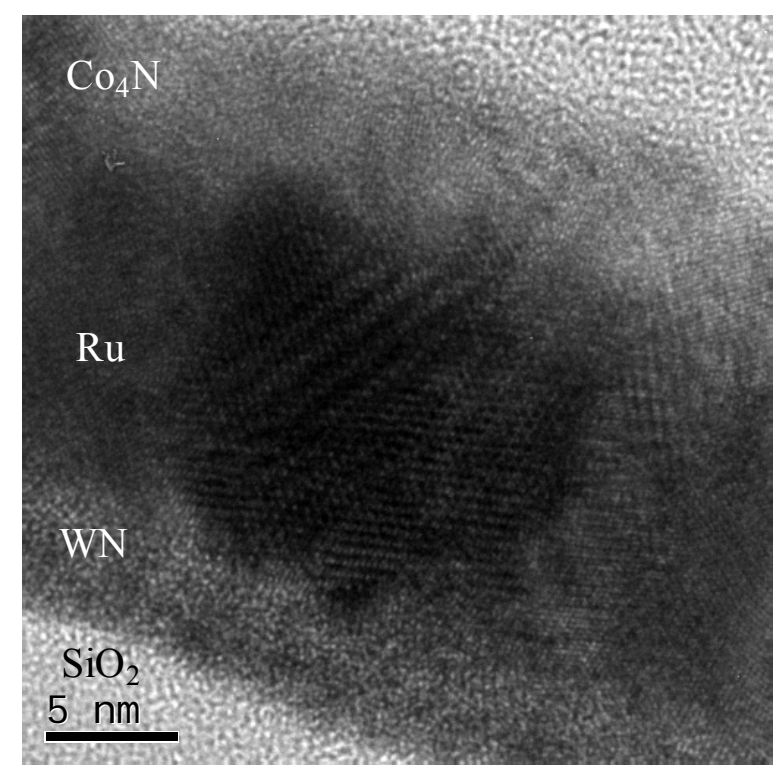

(a)

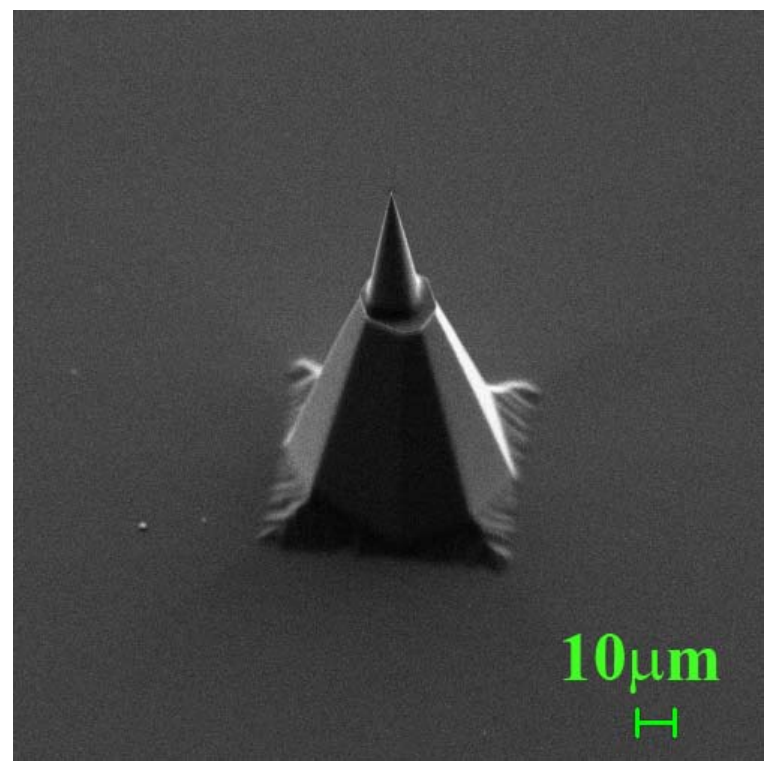

(b)

Figure 4. (a) Cross-sectional TEM image of the film stack on a planar $\mathrm{SiO}_{2} / \mathrm{Si}$ substrate;

(b) SEM image of the pre-sharpened micro-tip. 


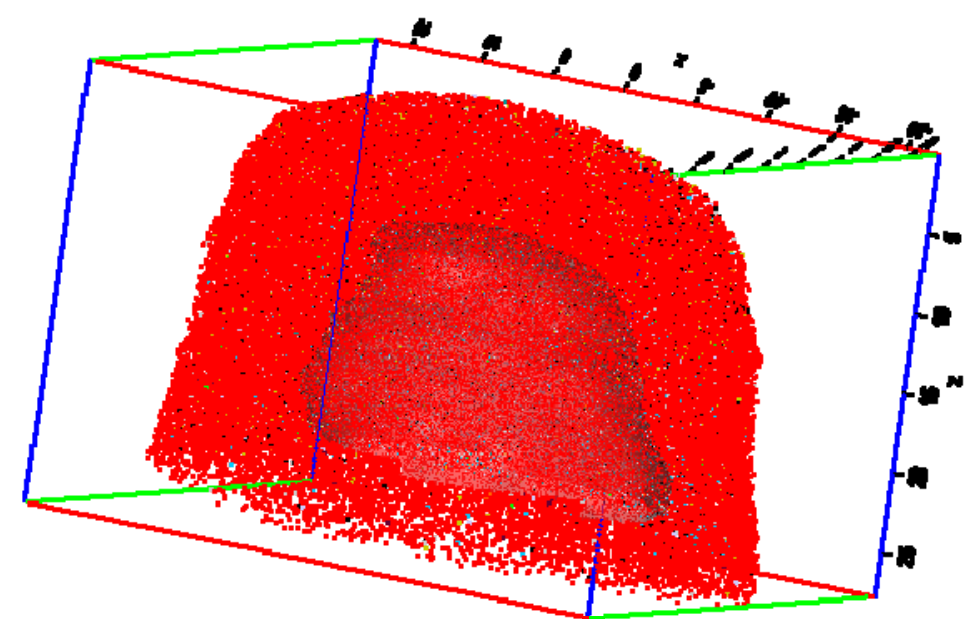

Figure 5. The 3D mapping of $\mathrm{Ru}$ atoms. 


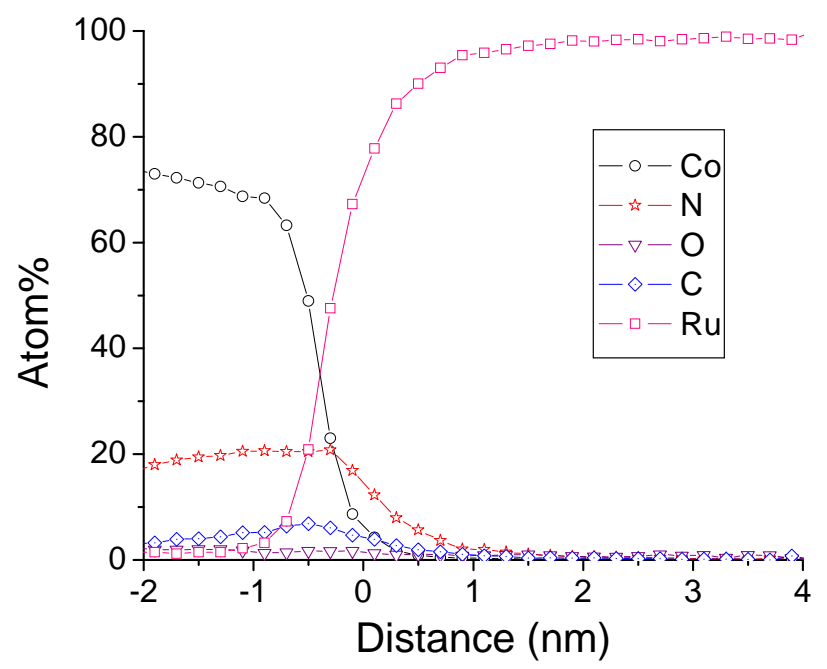

(a)

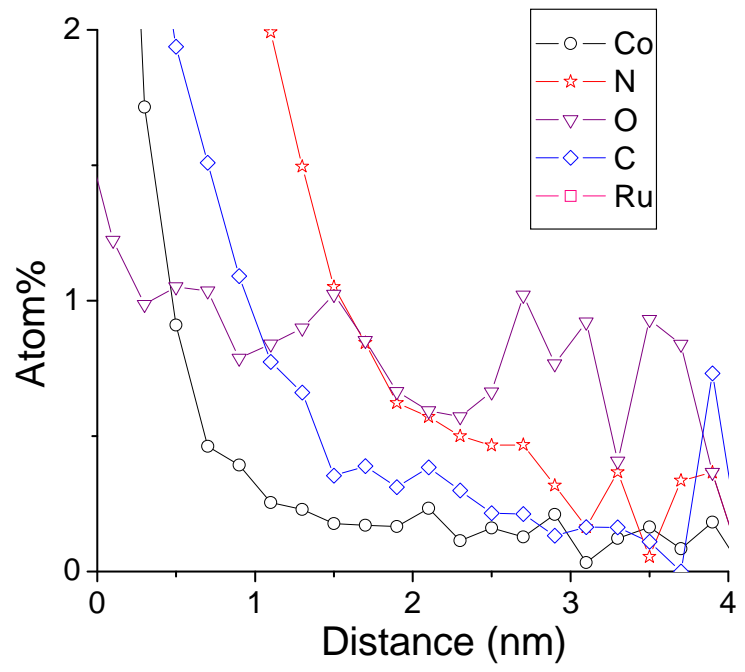

(b)

Figure 6. (a) The elemental depth profiles across the $\mathrm{Co}_{4} \mathrm{~N} / \mathrm{Ru}$ interface. (b) the details of impurity distribution across the interface. 


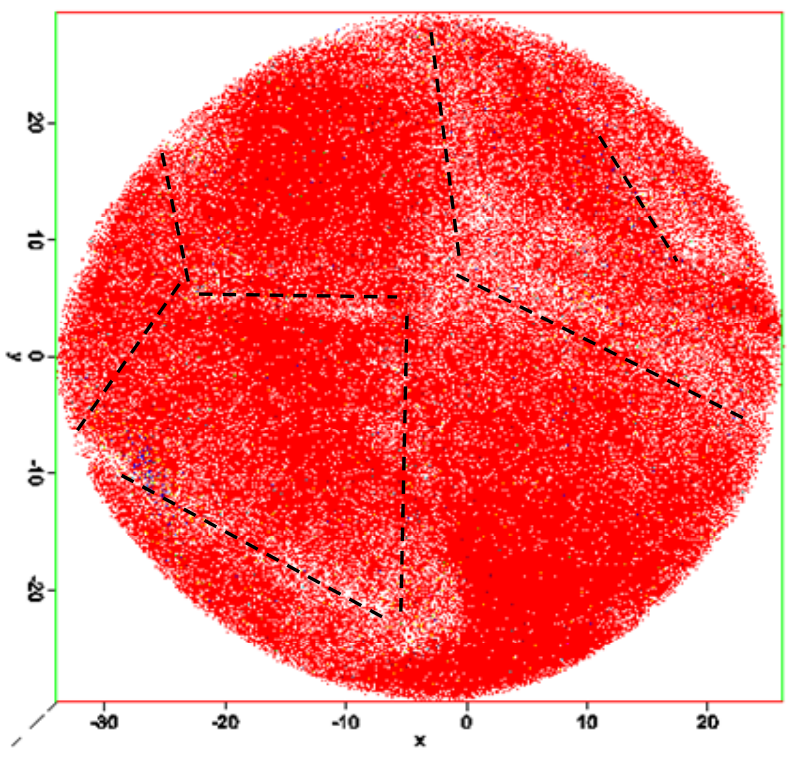

(a)

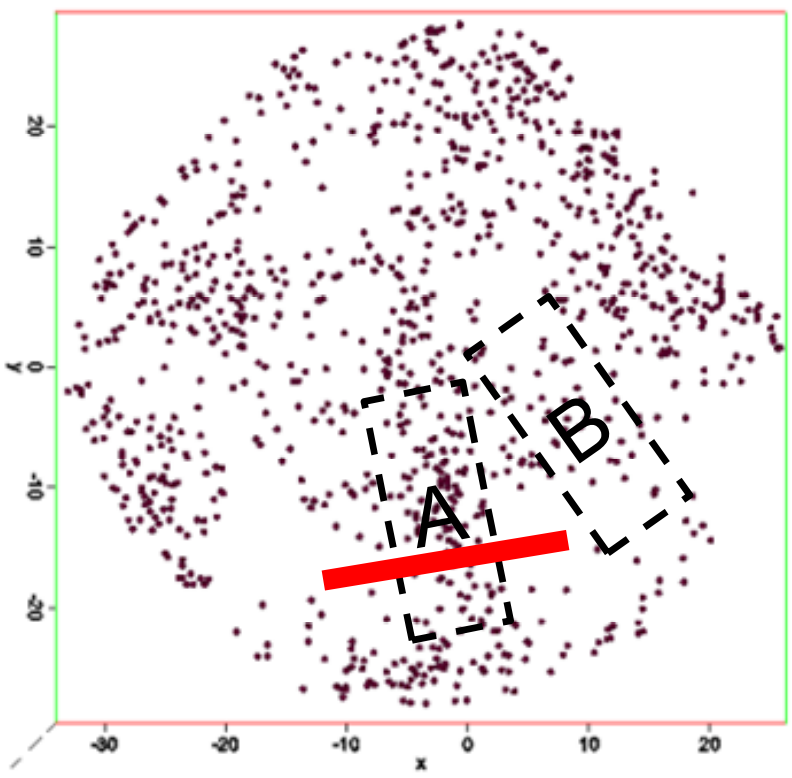

(b) 


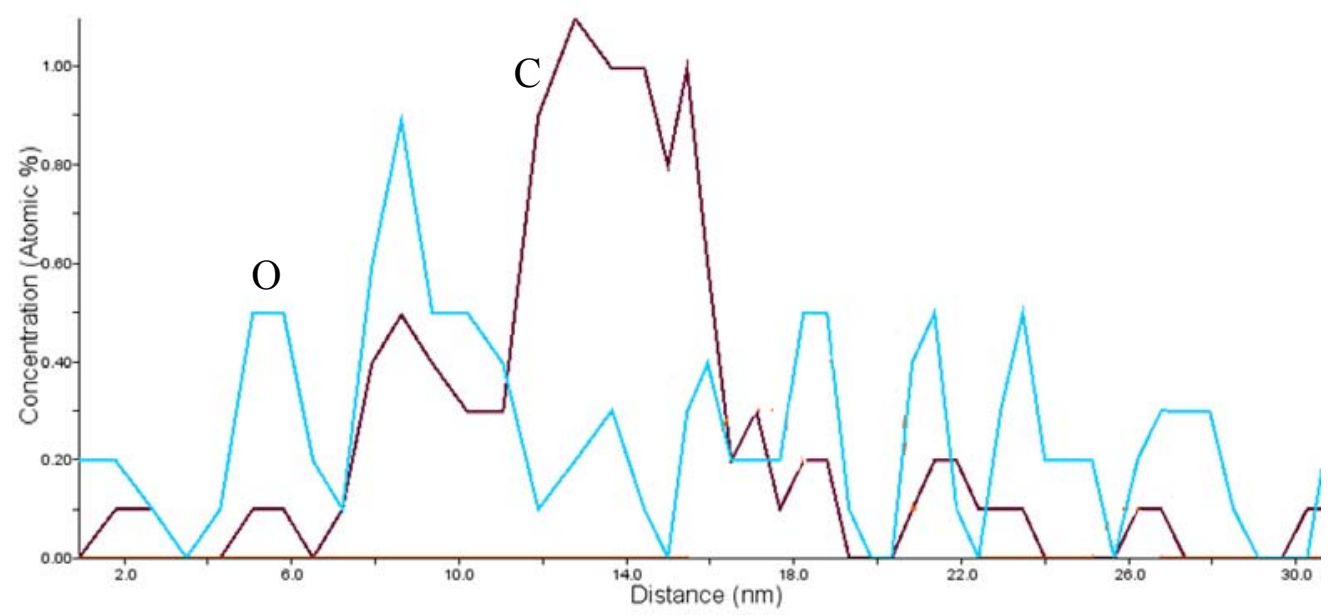

(c)

Figure 7. The $2 \mathrm{D}$ atom mappings of (a) Ru and (b) C. In (b), boxes A and B indicate the areas for local impurity concentration measurements. The line in (b) indicates the profiling location. (c) The $\mathrm{C}$ and $\mathrm{O}$ line profile across the GB. 


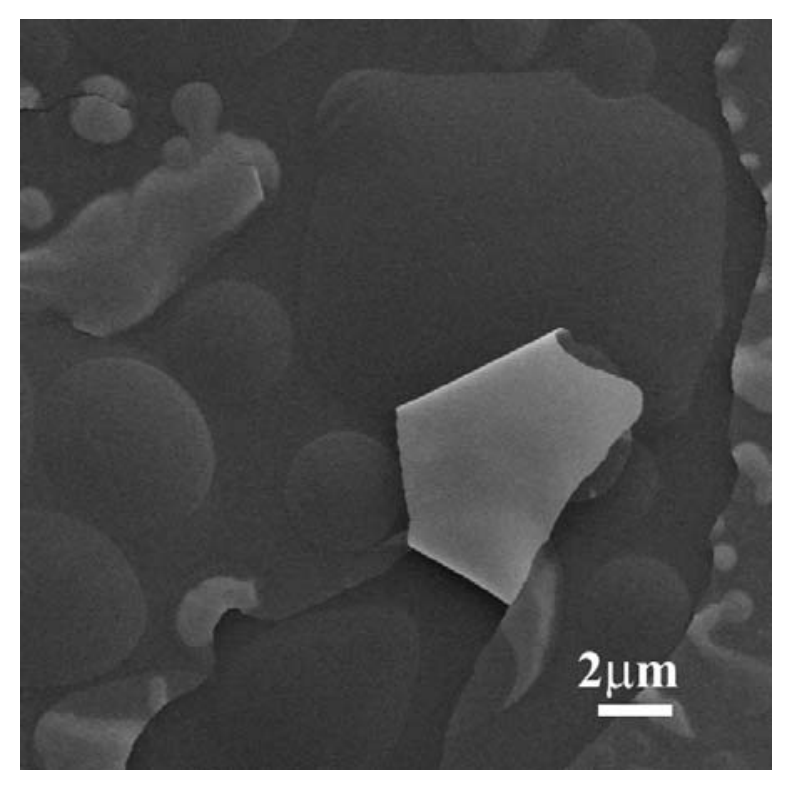

(a)

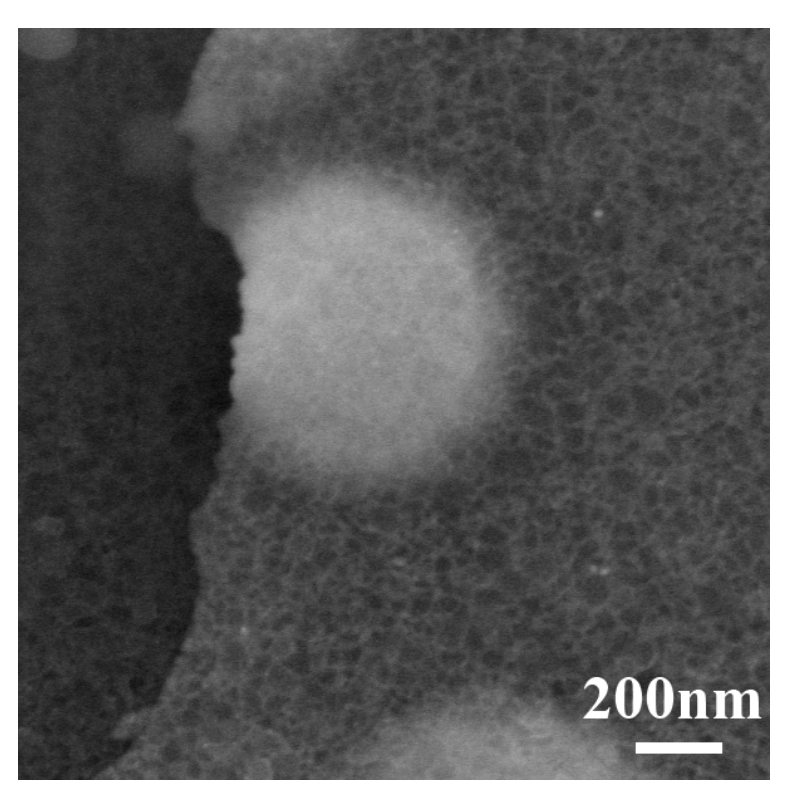

(b) 


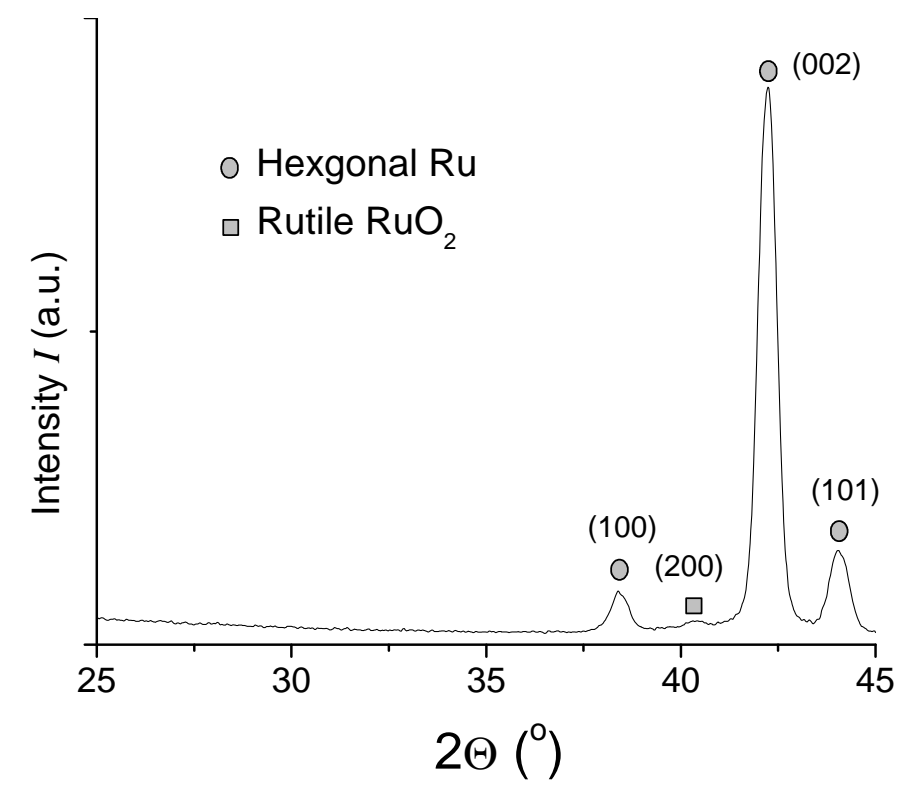

(c)

Figure 8. (a) low and (b) high magnification SEM images and (c) grazing angle XRD spectrum of Ru thin film deposited at $325^{\circ} \mathrm{C}$ and $E_{\mathrm{O}}>E_{\max }=0.04$ Torr $\cdot \mathrm{s}$. 


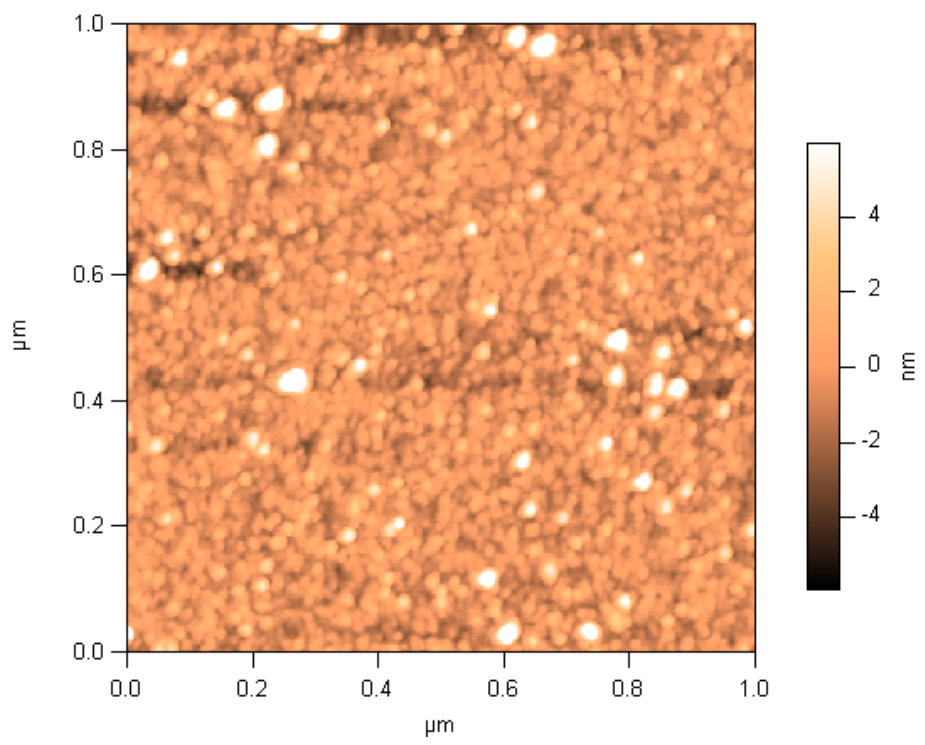

(a)

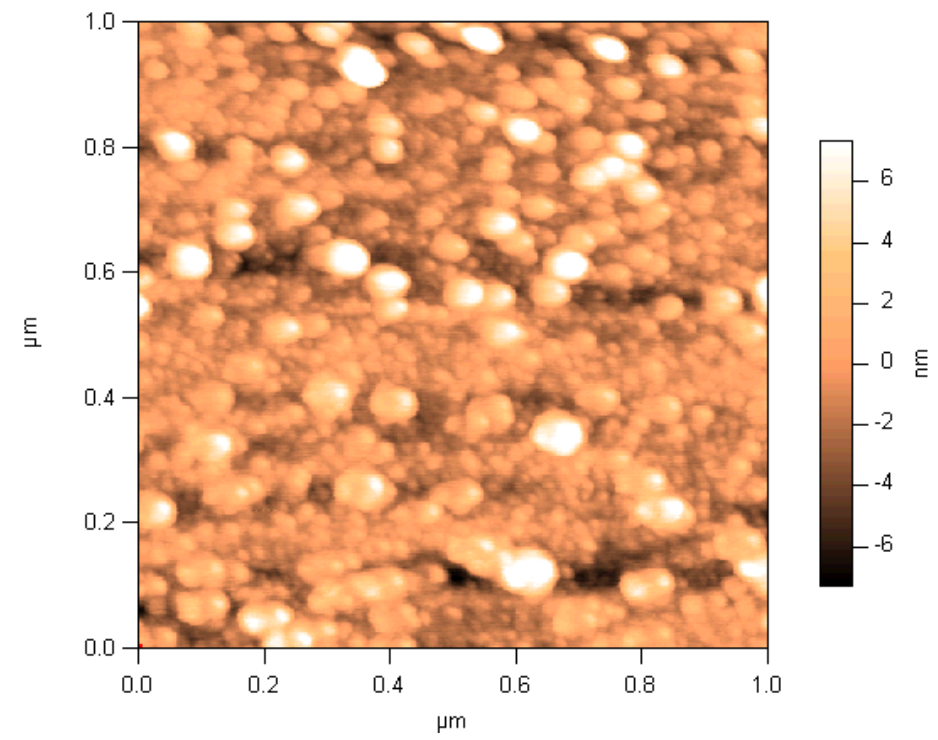

(b) 


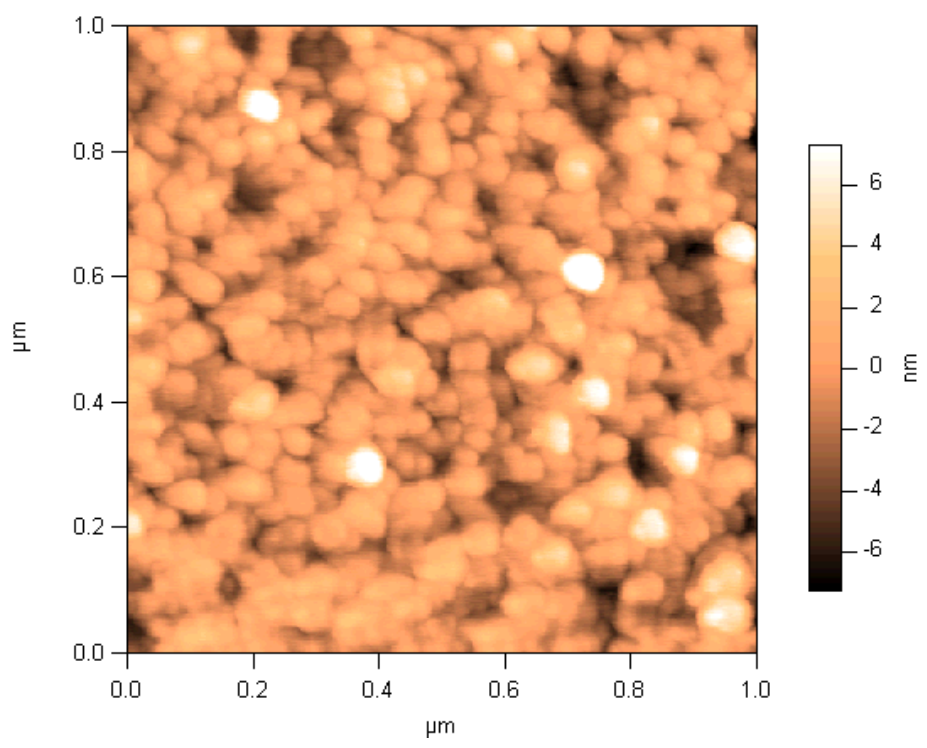

(c)

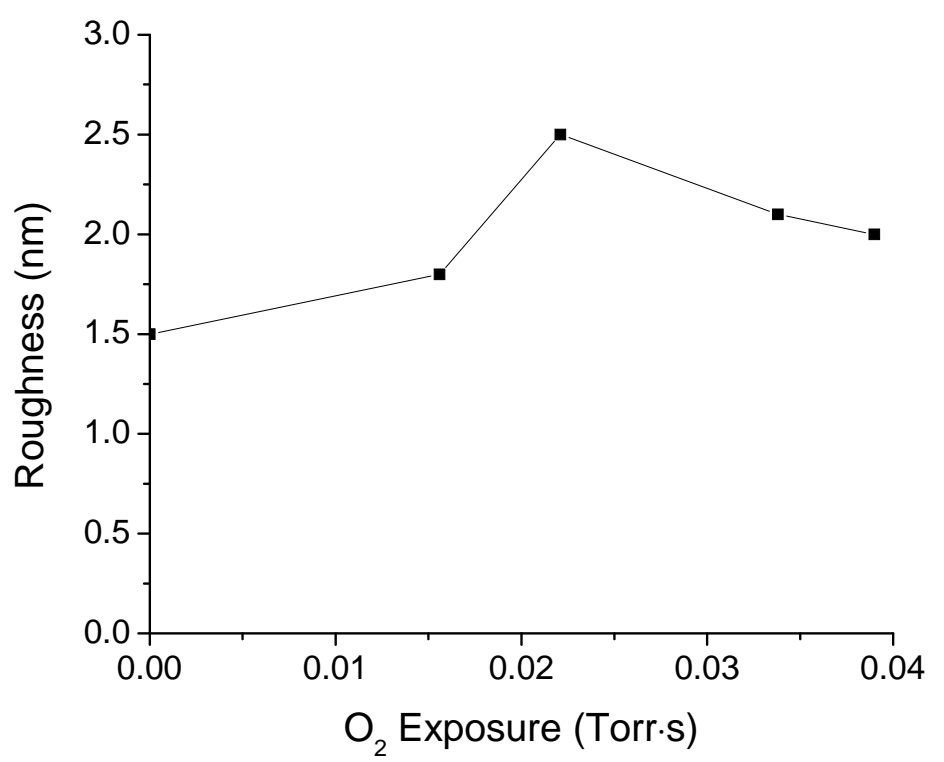

(d) 
Figure 9. AFM images of $\sim 30 \mathrm{~nm}$ Ru thin films deposited at $325^{\circ} \mathrm{C}$ with different $\mathrm{O}_{2}$

exposures: (a) 0 Torr $\cdot s$; (b) 0.022 Torr $\cdot s$; and (c) 0.034 Torr $\cdot s$. (d) Summary of the RMS roughness versus $\mathrm{O}_{2}$ exposure. 


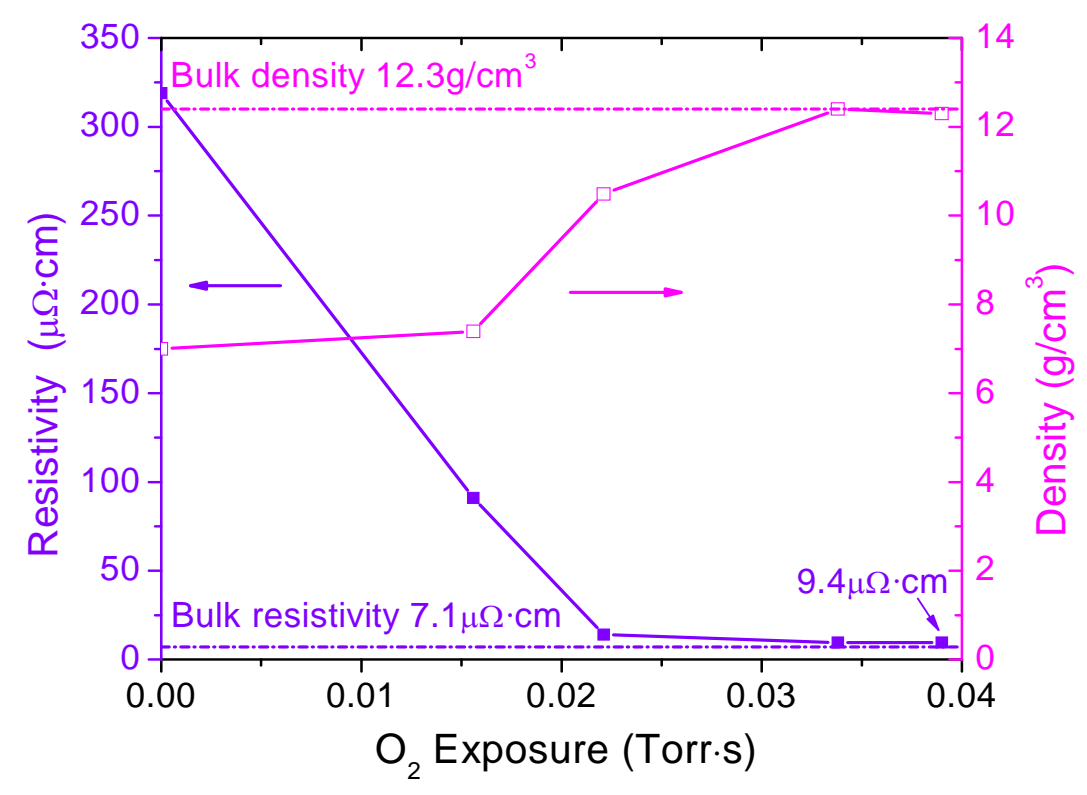

(a)

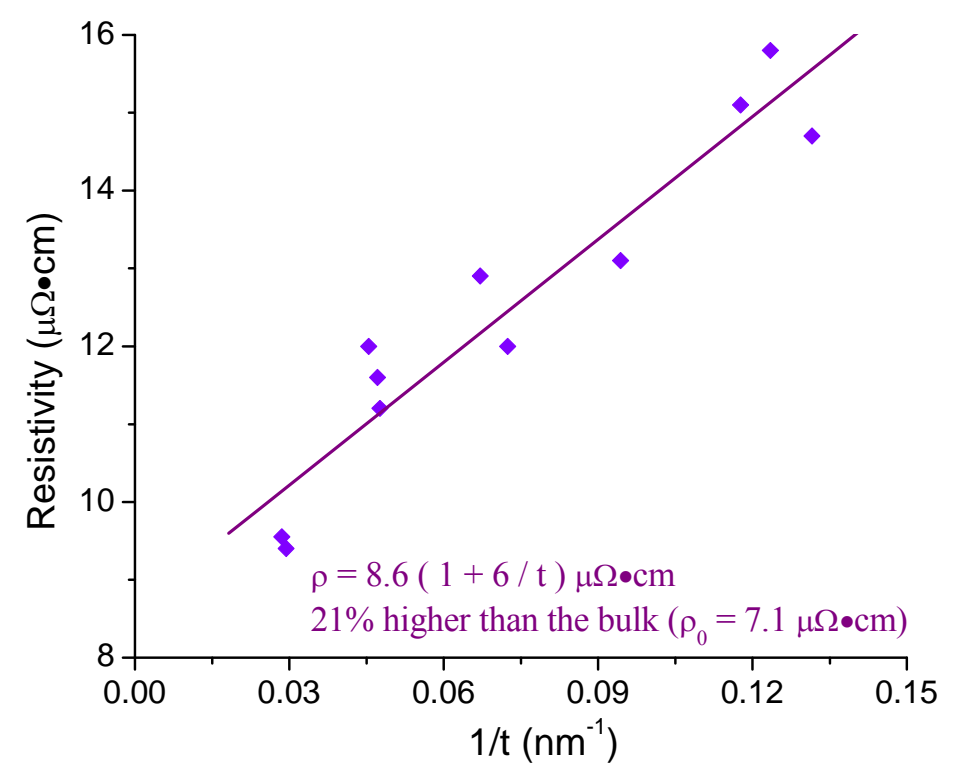

(b)

Figure 10. (a) Resistivity and density variation with $\mathrm{O}_{2}$ exposure for ALD films with thickness $\sim 35 \mathrm{~nm}$ deposited at $325{ }^{\circ} \mathrm{C}$; (b) the thickness dependence of resistivity. 


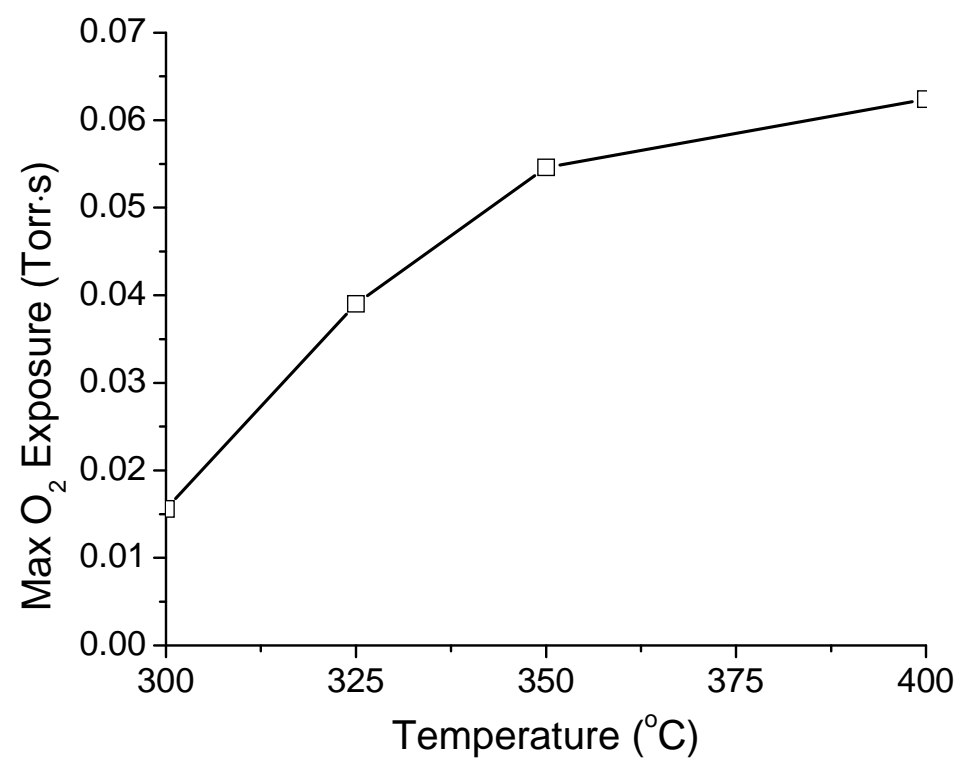

(a)

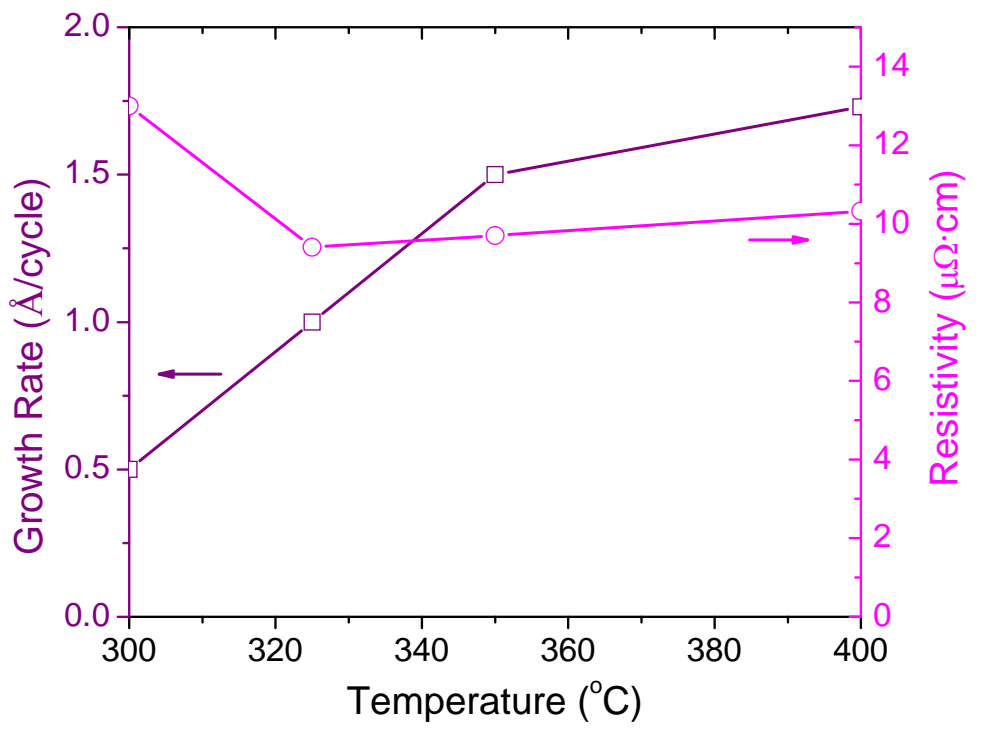

(b)

Figure 11. (a) The maximum $\mathrm{O}_{2}$ exposure at different deposition temperatures; (b) the growth rate and resistivity of $\sim 30 \mathrm{~nm}$ Ru films deposited at $E_{\max }$ and different deposition temperatures. 


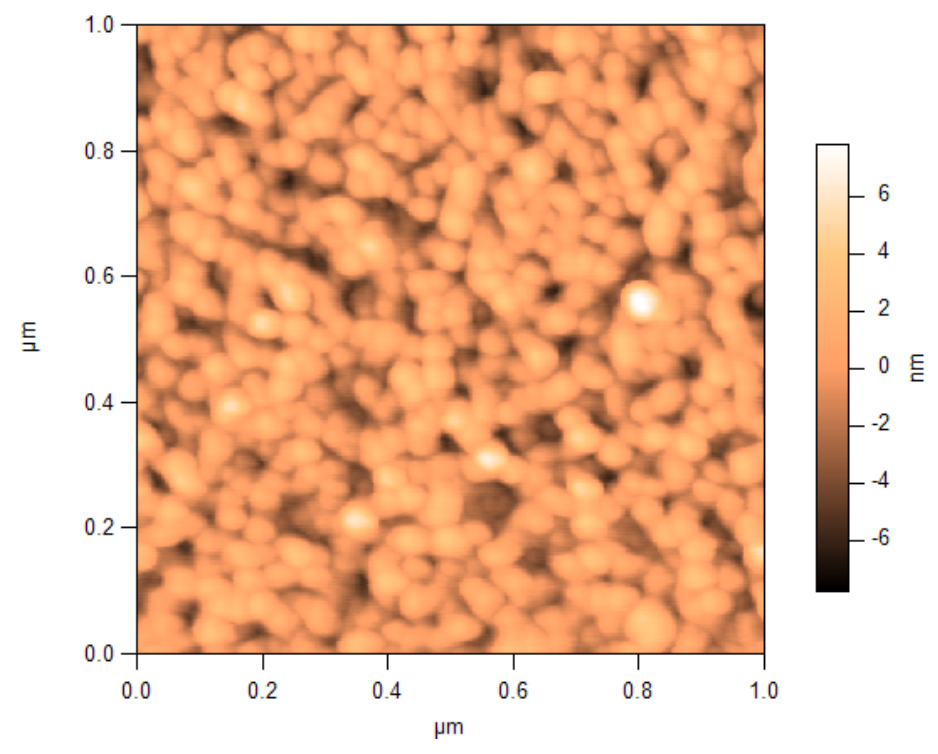

Figure 12 . AFM image of a $35 \mathrm{~nm}$ Ru thin film deposited at $400{ }^{\circ} \mathrm{C}$ and $E_{\max }$. The RMS roughness is $1.9 \mathrm{~nm}$. 